\title{
Compostos ativos de capim-cidreira (Cymbopogon citratus): uma revisão
}

\author{
Active compounds of lemon grass (Cymbopogon citratus): a review \\ Compuestos activos de hierba de limón (Cymbopogon citratus): una revisión
}

Recebido: 06/09/2021 | Revisado: 15/09/2021 | Aceito: 18/09/2021 | Publicado: 19/09/2021

\author{
Carla Cristina Alves de Oliveira \\ ORCID: https://orcid.org/0000-0002-5189-5161 \\ Faculdade Integrada Carajás, Brasil \\ E-mail: farmaceuticacarlacristina@gmail.com \\ Jânio Sousa Santos \\ ORCID: https://orcid.org/0000-0003-2180-1109 \\ Faculdade Integrada Carajás, Brasil \\ E-mail: santosjs.food@gmail.com
}

\begin{abstract}
Resumo
O presente estudo teve por objetivo apresentar um levantamento amplo e atual em relação aos compostos ativos do capim-cidreira (Cymbopogon citratus) e as funcionalidades por ele exercidas, tanto em in vitro quanto in vivo. Para tal foi realizada uma revisão da literatura, a qual reuniu o conhecimento científico sobre os aspectos das propriedades funcionais, do capim-cidreira. O levantamento teve como recorte temporal os últimos 10 anos (2011 a 2021). Foram utilizados os artigos em português e inglês. O levantamento bibliográfico apresenta os aspectos das plantas medicinais, sua utilização e seus compostos ativos. Apresenta as características do Cymbopogon citratus, seus compostos ativos e suas funcionalidades. Por meio das buscas verificou-se que esta planta possui compostos que lhe competem ação calmante, antifúngica, antimicrobiana, dentre outras. Concluiu-se assim que essas ações terapêuticas são produzidas, principalmente, pela presença do citral, componente em maior quantidade no óleo essencial desta erva, e por ter eficácia comprovada de seus benéficos e sendo este de fácil cultivo, tem-se nesta erva um fitoterápico de fácil acesso para população em geral, tanto para controle de moléstias humanas quanto para controle de pragas em animais.
\end{abstract}

Palavras-chave: Chá; Fenólico; Fitoterápico; Funcionalidade; Compostos ativos.

\begin{abstract}
The present study aimed to present a broad and current survey in relation to the active compounds of lemongrass (Cymbopogon citratus) and the functionalities exerted by it, both in vitro and in vivo. To this end, a literature review was carried out, which brought together the scientific knowledge on aspects of the functional properties of lemongrass. The survey had as a time frame the last 10 years (2011 to 2021). Articles in Portuguese and English were used. The bibliographic survey presents aspects of medicinal plants, their use and their active compounds. It presents the characteristics of Cymbopogon citratus, its active compounds and its functionalities. Through the searches it was found that this plant has compounds that are in charge of calming, antifungal, antimicrobial, among others. It was concluded that these therapeutic actions are produced mainly by the presence of citral, a component in greater quantity in the essential oil of this herb, and for having proven effectiveness of its benefits and being easy to grow, this herb is an herbal medicine. easily accessible to the general population, both for the control of human diseases and for the control of pests in animals.
\end{abstract}

Keywords: Tea; Phenolic; Herbal medicine; Functionality; Active compounds.

\section{Resumen}

El presente estudio tuvo como objetivo presentar un amplio y actual relevamiento en relación a los compuestos activos del limoncillo (Cymbopogon citratus) y las funcionalidades que éste ejerce, tanto in vitro como in vivo. Para ello, se llevó a cabo una revisión de la literatura, que reunió el conocimiento científico sobre aspectos de las propiedades funcionales del limoncillo. La encuesta tuvo como marco temporal los últimos 10 años (2011 a 2021). Se utilizaron artículos en portugués e inglés. El relevamiento bibliográfico presenta aspectos de las plantas medicinales, su uso y sus compuestos activos. Presenta las características de Cymbopogon citratus, sus compuestos activos y sus funcionalidades. A través de las búsquedas se encontró que esta planta tiene compuestos que se encargan de calmar, antifúngicos, antimicrobianos, entre otros. Se concluyó que estas acciones terapéuticas se producen principalmente por la presencia del citral, componente en mayor cantidad en el aceite esencial de esta hierba, y por tener probada eficacia de sus beneficios y ser fácil de cultivar, esta hierba es una planta medicinal. fácil acceso para la población en general, tanto para el control de enfermedades humanas como para el control de plagas en animales.

Palabras clave: Té; Fenólico; Medicina herbaria; Funcionalidad; Compuestos activos. 


\section{Introdução}

Desde a antiguidade, as sociedades humanas conservam informações e experiências sobre o ambiente que estão inseridas, para com ele interagir e prover suas necessidades de sobrevivência. Dentre as muitas práticas difundidas pela cultura popular, as plantas sempre tiveram grande importância, por diversas razões, sendo evidenciada suas potencialidades terapêuticas aplicadas ao longo das gerações (Badke, Budó, Titonelli, Zanetti, \& Heisler, 2012).

O estudo voltado para as plantas medicinais é feito pela ciência conhecida como fitoterapia, que, tendo sua origem no conhecimento e no uso popular, utiliza produtos de origem vegetal, para fins terapêuticos, afim de prevenir, atenuar ou curar algum estado patológico (Garlet, 2019; Lima, Alexandre, \& Santos, 2021).

O chá por exemplo, é uma das bebidas mais populares e consumidas no mundo. Esta bebida tem recebido muita atenção por se tratar de uma bebida funcional e por seus efeitos benéficos à saúde, associados aos seus compostos bioativos, como compostos fenólicos, aos quais são atribuídas diversas propriedades funcionais, com destaque a atividade antioxidante (Magalhães \& Santos, 2021).No Brasil o consumo de chá está diretamente relacionado às práticas curativas, tendo suas origens nas culturas indígenas, negras e europeias sendo as infusões de maior importância aquelas obtidas de ervas frescas com destaque para a camomila, capim-cidreira, erva-doce e hortelã (Brasil, 2021).

O capim-cidreira (Cymbopogon citratus), é uma erva nativa da Índia pertencente à família Poaceae. Seu cultivo se dá em várias áreas de clima tropical, uma vez que se desenvolve melhor em regiões de clima quente e úmido. É também chamado de capim-santo, capim-limão e erva-cidreira. Tem por características a formação de grandes touceiras e apresenta folhas verdeclaras muito cheirosas, ásperas, estreitas, longas e cortantes. A folha, quando amassada, exala um forte cheiro de limão (Santos, 2021).

Santos, (2021) ressalta que o aroma advindo das folhas é resultado de um óleo essencial conhecido como essência de lemongrass. Esse óleo é composto principalmente pelo citral, substancia que garante à planta sua ação calmante e espasmolítica. No óleo essencial C. citratus encontra-se variadas classes de metabólitos secundários que apresentam uma vasta variedade de atividades biológicas. O esclarecimento realizado por Shah, et al. (2011), sobre o óleo, revelou a presença de vários compostos potencialmente bioativos no óleo, como fenóis, terpenos, alcoóis, cetonas, ésteres e principalmente aldeídos têm sido constantemente registrado. Apesar de que mirceno e limoneno sejam compostos aromáticos, citral e geraniol ambos atuam como antimicrobiano e inseticida, respectivamente (Aluyor, \& Oboh, 2014).

O capim- cidreira é predominantemente usado na forma de infusão de folhas frescas e secas ou por meio do seu óleo essencial (Costa, 2015). Sob a forma de infusão, tem efeito sedativo, calmante do sistema nervoso. Porém, em estudo apresenta-se com propriedades antiespasmódica, analgésica, bactericida, inseticida, inibitória do crescimento de fungos e antimutagênica (Brito, Garruti, Alves, \& Blank, 2011).

Em um estudo fitoquímico conduzido por Roriz, Barros, Carvalho, Santos e Ferreira (2014), avaliou-se os compostos antioxidantes do capim- cidreira, e constou-se que o mesmo apresentou capacidade de remoção de ânion superóxido e radical hidroxila, revelando que estes compostos possuem um efeito protetor contra as espécies reativas que estão envolvidas em doenças inflamatórias e degenerativas.

Em estudo realizado por Ramos, Santos, Daguer, Cruz e Granato (2017) foi constatado a presença de compostos fenólicos em extrato aquoso de Cymbopogon citratus $333 \pm 11 \mathrm{mg}$ de ácido gálico equivalente por litro de extrato aquoso. Além disso relataram atividade antioxidante frente ao radical DPPH apresentando 6\% de inibição do radical, assim como, capacidade redutora total de $302 \pm 13 \mathrm{mg}$ de quercetina equivalente por litro de extrato.

Os chamados princípios ativos são as substâncias químicas presentes nas plantas, que vão atuar como medicinais, promovendo reações no organismo que as utiliza. Tais substâncias são sintetizadas conforme a luz e os nutrientes que a planta recebe ou conseguiu extrair do solo (Garlet, 2019). Desta forma, o presente estudo tem por objetivo apresentar um 
levantamento amplo e atual em relação aos compostos ativos do capim-cidreira (Cymbopogon citratus) e as funcionalidades por ele exercidas, tanto em in vitro quanto in vivo.

\section{Metodologia}

Foi realizada uma revisão integrativa da literatura, a qual teve como finalidade reunir o conhecimento científico sobre os aspectos das propriedades funcionais, do capim-cidreira. O levantamento teve como recorte temporal os últimos 10 anos (2011 a 2021). Para a busca dos artigos foram utilizadas as seguintes palavras-chaves: Capim-cidreira, Cymbopogon citratus, compostos ativos. Foram utilizados artigos em português e inglês.

\section{Resultados e Discussão}

\section{Plantas medicinais}

A população faz uso de variadas práticas com o objetivo de tratar doenças e sintomas que ameaçam a sua saúde. Embora o significativo avanço tecnológico e das expressivas melhorias apresentadas na área da saúde nos últimos anos, o uso das plantas medicinais como forma de tratamento complementar é ainda bastante comum. Há alguns anos a Organização Mundial de Saúde (OMS) estimou que aproximadamente $80 \%$ da população mundial já faziam uso, e confiavam, nos produtos medicinais de origem vegetal (Stefanello et al., 2018).

A Agência Nacional de Vigilância Sanitária - Anvisa, define como plantas medicinais aquelas com capacidade de aliviar ou curar enfermidades e têm por prática o seu uso como remédio em uma população ou comunidade. Para usá-las, é necessário conhecer a planta e saber onde colhê-la, e como prepará-la. Habitualmente são usadas na forma de chás e infusões (Brasil, 2020).

Os conhecimentos práticos das comunidades tradicionais sobre as plantas medicinais estão profundamente ligados aos recursos naturais disponíveis e a seu patrimônio cultural, sendo uma reprodução sócia bicultural e econômica de seus antepassados, que vem sendo transmitido para os dias atuais. Visto que, essas plantas e seus derivados vêm, há muito tempo, sendo usadas pelas populações locais, nos seus cuidados básicos de saúde, com destaque para as comunidades indígenas, quilombolas e rurais, através da transmissão oral de conhecimentos entre as gerações (Lacerda et al., 2013).

Vale ressaltar ainda, que o uso das plantas medicinais ou dos fitoterápicos pode ser eficaz no tratamento de diversas patologias, desde que observados alguns critérios, tais como: identificação das espécies, indicação conforme quadro clínico e preparação adequada. Podendo ser de uso interno (ingeridas como chás e xaropes) e de uso externo ou tópico (na pele ou nas mucosas das cavidades naturais). Sendo as formas mais comumente empregadas nos tratamentos caseiros os chás (infusão, decocção e maceração), gargarejo, cataplasma, compressa, inalação, banho de assento, xarope, pó e tintura (Garlet, 2019).

\section{Cymbopogon citratus}

A espécie Cymbopogon citratus (DC) Stapf pertence à família Poaceae e tem sua origem na Índia e aclimatada no Brasil. É amplamente conhecida, sendo chamada popularmente de erva-cidreira, capim-limão e capim-santo. Seu cultivo se dá em todos os países na região dos trópicos. É cultivado a pleno sol, vegetando em qualquer tipo de solo, desde que bem drenado e fértil. É uma planta herbácea, com longas folhas aromáticas, estreitas, ágidas e ásperas, com nervuras centrais proeminentes. Suas flores, dificilmente são vistas, pois reúnem em panículas de pequenas espigas escuras (Brito et al., 2011).

O capim-cidreira adapta-se a condições variadas de clima e solo, preferindo climas quentes e úmidos, com chuvas bem distribuídas e temperatura média elevada, não resiste a regiões frias e sujeitas a geadas. (Oliveira, Barcelos, Ferreira, Rodrigues, \& Sardinha, 2019). 
O gênero Cymbopogon é largamente distribuído nas regiões tropicais e subtropicais da África, Ásia e América. Composto por 144 espécies, este gênero é bastante popular por seu alto teor de óleos essenciais que têm sido usados para aplicações em cosméticos, produtos farmacêuticos e perfumaria (Avoseh, Oyedeji, Rungqu, Chungag, \& Oyedeji ,2015).

No Brasil Cybopogon citratus é conhecido popularmente como capim-limão, capim-cidró, capim-cheiroso, capimcidreira, capim-cidrão, citronela-de-java e erva-cidreira. Pertence à família das Gramíneas, subfamília Panicoideae. É uma planta nativa da Europa, mas que seu cultivo se disseminou em diversas partes do mundo, inclusive no Brasil (Lins et al., 2015).

Toda planta medicinal só é medicamento quando utilizada de forma correta, portanto, a recomendação para uso é identificar o seu princípio ativo ou tê-lo evidenciado farmacologicamente (Fonseca \& Giotto, 2021).

Brasil, (2011) indica o preparo por infusão na dosagem de 1-3 g de folhas em $150 \mathrm{~mL}$ de água. Tendo como indicação o uso como antiespasmódico, ansiolítico e sedativo leve. Sendo recomendado uso interno por pessoas acima de 12 anos e tomar $150 \mathrm{~mL}$ do infuso, $5 \mathrm{~min}$ após o preparo, duas a três vezes ao dia. Ressaltando que a preparação pode potencializar o efeito de medicamentos sedativos. De acordo com Lins et al. (2015) o C. citratus apresenta metabólitos secundários, como alcaloides, terpenoides, flavonoides, carotenoides, taninos, glicosinolatos, pigmentos, ceras, óleos, esteróis e clorofila.

\section{Metabolitos secundários de Cymbopogon citratus}

Metabolismo é conceituado como o conjunto total das transformações das moléculas orgânicas, catalisadas por enzimas, que acontece nas células vivas, suprindo de energia o organismo, renovando suas moléculas e assegurando a ininterrupção do estado organizado. Essas reações têm certa direção em virtude da presença de enzimas específicas, estabelecendo, assim, as rotas metabólicas, objetivando o aproveitamento de nutrientes para satisfazer as exigências fundamentais da célula. Além do metabolismo primário, responsável pela síntese de celulose, lignina, proteínas, lipídeos, açúcares e outras substâncias importantes para a realização das funções vitais, as plantas também possuem o chamado metabolismo secundário (Pereira \& Cardoso, 2012).

Em geral, os metabólitos secundários apresentam estrutura complexa, baixo peso molecular, exercem atividades biológicas marcantes e, diferentemente dos metabólitos primários, apresentam-se em baixas concentrações e em determinados grupos de plantas (Silva \& Lima, 2015). A característica mais específica do metabolismo secundário é a sua ampla plasticidade genética e diversidade que asseguram adaptações flexíveis à mediação de fatores bióticos e abióticos (Rezende, Rosado, Moreira, \& Carvalho, 2016).

Essas substâncias secundárias são os chamados princípios ativos vegetais habitualmente encontrados em variados produtos e terapias. São substâncias constituídas a partir de produtos da fotossíntese com a finalidade de defesa para a planta, e responsável pelo efeito medicinal de uma planta (Rezende et al., 2016). Os metabólitos secundários podem ser divididos em três grupos principais: os terpenóides, compostos fenólicos e compostos nitrogenados (Miranda, 2012).

\section{Terpenos}

Quimicamente, terpeno é definido como "alcenos naturais", ou seja, apresenta uma dupla ligação carbono-carbono caracterizado como um hidrocarboneto insaturado. Deste modo, se o terpeno contém oxigênio, é denominado de terpenoide, podendo assim apresentar diferentes funções químicas, entre as quais: ácidos, álcoois, aldeídos, cetonas, éteres, fenóis ou epóxidos terpênicos (Mcmurry, 2011). A unidade isoprênica é a característica principal dos terpenos, que é composta por cinco carbonos. Sendo a classificação dos terpenos dada em função do número de unidade de isopreno (Miranda, 2012).

Os terpenos são os componentes mais importantes dos óleos essenciais. A maioria deles contém de 10 a 30 átomos de carbono (Silva \& Lima, 2015). Estas substâncias integram um vasto grupo de moléculas orgânicas produzidas como 
metabólitos secundários principalmente nas plantas para evitar danos promovidas por agentes externos. Assim, os terpenos apresentam reconhecida atividade antimicrobiana (Felipe \& Bicas, 2017).

A espécie Cymbopogon citratus possui em suas folhas o óleo essencial, que contém em maior quantidade substâncias do grupo monoterpenos: citral 65-80\% (Port's, 2011). O mirceno também é apontado como sendo um terpeno característico da espécie. Sendo sua quantidade presente de 27,04\% no óleo essencial (Gbnou et al., 2013). Outro terpeno característico é o limoneno, um dos monoterpenos mais frequentes no óleo essencial. Em alguns estudos também foram isolados terpenos como o terpinoleno, o ocimeno, o pinemo, o cariofileno, o felandreno e o oxobisaboleno (Roma, 2020; Jesus, 2019; Oladej, Adelow, Ayodele \& Odelabe, 2019).

\section{Compostos fenólicos}

Define-se compostos fenólicos, como substâncias que têm um anel aromático contendo um ou mais substituintes hidroxílicos, incluindo seus grupos funcionais. Estão amplamente distribuídos no reino vegetal, englobando desde moléculas simples até outras com alto grau de polimerização (Rocha et al., 2011).

Os compostos fenólicos são considerados um dos grupos de compostos bioativos responsáveis pelos efeitos benéficos à saúde. Embora existam outros mecanismos, o modo de ação mais citado é a atividade antioxidante pela habilidade de sequestrar espécies reativas de oxigênio e quelar íons metálicos (Port's, 2011). Estes compostos configuram-se entre os metabólitos secundários mais importantes e difundidos no reino vegetal, concentrando-se principalmente nas partes aéreas das plantas. Dentre as principais funções biológicas destes compostos pode-se destacar a atração de polinizadores, proteção contra nocivos, colaboração com hormônios no processo de crescimento, inibição da ação de certas enzimas e proteção à radiação ultravioleta (Souza et al., 2015).

Por conta da sua grande atividade antioxidante, diversos compostos fenólicos desempenha um papel importante nos processos de diminuição do risco das doenças cardiovasculares e podem atuar sobre o estresse oxidativo, ligado a diversas patologias crônico-degenerativas, como o diabetes, o câncer e processos inflamatórios (Rocha et al., 2011). Os compostos fenólicos das plantas se enquadram em várias categorias, tais como fenóis simples, ácidos fenólicos (derivados do ácido benzóico e cinâmico), cumarinas, flavonóides, estilbenos, taninos condensados e hidrolisáveis, lignanas e ligninas (Azevedo et al., 2011).

\section{Ácidos fenólicos}

Os ácidos fenólicos são constituídos por duas classes: os derivados de ácido hidroxibenzoico e os derivados de ácido hidroxicinâmico. Os originários de ácido hidroxibenzoico apresentam esqueleto C6-C1 e alguns exemplos desta classe são os ácidos p-hidroxibenzoico, protocatecuico e gálico. Já os derivados de ácido hidroxicinâmico têm esqueleto C6-C3 e são exemplos desta classe os ácidos cumárico, cafeico e ferúlico (Magalhães \& Santos, 2021).

Os ácidos hidroxibenzoicos são constituintes das complexas estruturas dos taninos hidrolisáveis e são menos abundantes nos vegetais consumidos pelos humanos. Já os ácidos hidroxicinâmicos acham-se presentes em diversos alimentos e bebidas de origem vegetal, tais como o café, erva mate, maçã, ameixa e outras frutas, crucíferas, cereais, entre outros. Exemplos desta classe de compostos são o ácido cafeico, p-cumárico, ferúlico e sinápico que, na maioria dos alimentos, se encontram esterificados ao ácido quínico, ácido tartárico ou carboidratos e derivados, podendo ser encontrado também na forma livre em alimentos, como o tomate e a cerveja (Oliveira \& Bastos, 2011). 


\section{Flavonoides}

Estes são apontados como um dos maiores grupos de metabólitos secundários das plantas, sendo bastante encontrados em frutas, folhas, chás e vinhos. Estão diariamente presentes na dieta do homem, e são apontados por especialistas da área da saúde como protetores naturais do organismo contra vários efeitos adversos (Rodrigues et al., 2015).

São substâncias aromáticas com 15 átomos de carbono em seu núcleo fundamental (o núcleo flavan C6 -C3 - C6), constituído de duas fenilas ligadas por uma cadeia de 3 carbonos entre elas (Souza et al., 2015).

As folhas e rizomas do capim-cidreira possuem diferentes flavonoides como luteolina, quercetina, campferol, isoorientina e isoscoparina (Oliveira et al., 2019). Estas classes polifenólicas, vem se destacando desde a década de 80, por possuírem importantes propriedades farmacológicas. Até o momento, em testes feitos com animais, estes compostos apresentaram ação terapêutica, aos sistemas imunológico, circulatório, cardiovascular e nervoso (Rodrigues et al., 2015).

Os flavonoides são exemplos de compostos fenólicos com alto poder antioxidante e inúmeras plantas possuem em sua composição esse antioxidante natural (Silva et al., 2017). Isso acontece por intermédio da atividade de neutralização de radicais exercida por esta classe de componentes, principalmente à sua estrutura química, do número e posição dos grupos hidroxila e da natureza das substituições nos anéis aromáticos com propriedades de oxirredução (Oliveira et al., 2019).

\section{Taninos condensados e hidrolisáveis}

Presentes na maioria das plantas, os taninos podem ter sua concentração variando de acordo com os tecidos vegetais, assim como a idade e tamanho da planta, da parte coletada, da época ou, ainda, do local de coleta. São classificados em dois grupos principais, os quais as estruturas são bastante diferentes entre si, apesar de todos terem molécula poli-hidroxifenóis ou seus derivados (Bernardes et al., 2011). Habitualmente são encontrados em caules, cascas, folhas, flores ou sementes, abrigados dentro dos vacúolos, principalmente em plantas dicotiledôneas (Tontini, Silva, Souza, \& Poli 2021).

Os dois grupos em que os taninos são divididos são baseados nos tipos estruturais: hidrolisável e condensado. Os hidrolisáveis, são vulneráveis a degradação por hidrólise química ou enzimática nas diversas unidades estruturais que os constituem. Têm em sua constituição uma parte fenólica (ácido gálico e/ou ácido hexahidroxidifênico) e uma unidade de hexose (normalmente a glucose) ligadas por um éster (Tontini et al., 2021). Já os taninos condensados são formados por monômeros do tipo catequina, conhecidos por flavonoides, e estão presentes, essencialmente, na casca das árvores (Azevêdo, Paes, Colegare, \& Santana, 2017). São também responsáveis pela pigmentação vermelha, roxos e azuis nas flores, frutos, sementes, caules e folhas (Tontini et al., 2021).

\section{Alcaloides}

Dentre os principais constituintes de C. citratus, estão os compostos fenólicos e os alcalóides (Souza et al., 2015). Estes últimos são compostos orgânicos cíclicos que contem nitrogênio em um estado de oxidação negativo e de disposição limitada entre os seres vivos. Supõe-se que esta classe compreenda mais de 4.000 compostos, que representam por volta de $15 \%$ a $20 \%$ dos produtos naturais conhecidos e que está dividida em diversos grupos, tropânico, quinolínico, piperidínico, entre outros. Tendo como destaque o grupo dos alcaloides indólicos, por sua grande variedade em termos de estrutura e de propriedades farmacológicas, principalmente antineoplásicas (Marques \& Lopes, 2015).

\section{Espécies reativas}

Radicais livres são moléculas orgânicas e inorgânicas ou átomos que contêm um ou mais elétrons não pareados na última camada eletrônica, com existência independente. São altamente reativos, capaz de reagir com qualquer composto situado próximo à sua órbita 12 externa, passando a ter uma função oxidante ou redutora (Oliveira et al., 2019). Alguns dos 
radicais livres são espécies reativas procedentes do oxigênio, instáveis e altamente reativas, que são resultado do processo metabólico aeróbico tradicional, no entanto tornam-se prejudiciais quando seus níveis se encontram alterados. Esse desequilíbrio é chamado de estresse oxidativo e pode resultar na degradação de estruturas biológicas essenciais para o funcionamento orgânico celular e oportunizar o desenvolvimento ou agravamento de doenças (Vellosa et al., 2020).

As substâncias antioxidantes, são aquelas capazes de impedir a oxidação ou que mesmo em baixa concentração comparada ao substrato oxidável, diminui ou inibe a oxidação deste substrato. Do ponto de vista biológico, antioxidante são compostos que fazem a proteção dos sistemas biológicos combatendo os efeitos negativos dos processos ou reações que levam à oxidação de moléculas ou estruturas celulares (Prevedello \& Comachio, 2021). Segundo Port's (2011), nas infusões da espécie Cymbopogon citratus encontrou-se resultados de forte atividade antioxidante, tanto para o DPPH, bem como para inibição da peroxidação lipídica.

\section{Funcionalidades advindas do capim-cidreira}

O capim-cidreira é amplamente utilizado pela industrial. Suas folhas desidratadas são usadas, especialmente, pela indústria alimentícia para a fabricação de chás. Já o óleo essencial, extraído das folhas, é utilizado tanto na indústria alimentícia, como flavorizante e aromatizante, quanto na indústria farmacêutica na produção de fitoterápicos, inseticidas, cosméticos e perfumaria (Gomes \& Negrelle, 2015).

O Capim cidreira é um fitoterápico que oferece benefícios tais como; ação anti-hipertensiva, diurética, calmante, antimicrobiana, age no controle das cólicas abdominais e analgésico (Pereira \& Ruyz, 2018). As atividades antimicrobianas e antifúngica do óleo essencial de C. citratus foram conferidas ao citral. O mirceno por sua vez, não apresentou atividade antimicrobiana, mas, em associação com o citral potencializou seu efeito. O citral também é matéria prima de importantes compostos químicos identificados como iononas, usados na perfumaria e na síntese da vitamina A (Santos et al., 2009).

Boukhatem, Kameli, Ferhat, Saidi e Tayebi (2014) em seu estudo observou que o óleo de capim-cidreira possui potente atividade antimicrobiana contra bactérias Gram positivas e apresentou o mais forte efeito antifúngico contra Candida albicans e C. parapsilosis. A concentração inibitória mínima variou de 0,019 a 1,25 mg/mL para bactérias Gram-positivas e leveduras, indicando Staphylococcus aureus, S. epidermidis e C. albicans como as cepas mais suscetíveis a ação do óleo.

Em estudo realizado por Lucena et al., (2015) por meio da técnica de microdiluição contra cepas padrões e multirresistentes de Escherichia coli, Staphylococcus aureus e Pseudomonas aeruginosa. Os autores observaram que o óleo apresentou interferência sobre a atividade de aminoglicosídeos frente às linhagens destes microrganismos. E que quando utilizados em conjunto com antibióticos os efeitos destes é potencializado.

Sobre a ação antioxidante e antifúngica Guimarães, Cardoso, Sousa, Andrade, e Vieira (2011) realizaram análise qualitativa do óleo essencial, por meio de cromatografia gasosa acoplada à espectrometria de massa, visando avaliar a atividade antioxidante e osefeitos fungitóxicos do óleo essencial de capim-limão e do seu constituinte majoritário citral sobre o crescimentoe/ou inibição micelial dos fitopatógenos Fusarium oxysporum cubense, Colletotrichum gloeosporioides, Bipolaris sp. e Alternaria alternata.

Para avaliação da ação antifúngica os pesquisadores utilizaram o método bioanalítico in vitro, onde avaliaram o efeito dos vapores do óleo essencial de capim-limão e de seus constituintes majoritários (citral e mirceno) sobre o crescimento e/ou inibição micelial dos fitopatógenos estudados. Já para a atividade antioxidante empregaram os métodos de redução do radical livre DPPH (2,2-difenil-1-picrilhidrazil) e o ensaio de oxidação do sistema $\beta$-caroteno/ácido linoléico, sendoutilizados como controle positivo os compostos timol e $\alpha$-tocoferol. Puderam verificar que o óleo essencial de capim-limão e o seu constituinte majoritário citral apresentaram atividade antioxidante apenas no ensaio de oxidação do sistema $\beta$-caroteno/ácido linoleico. Verificaram também que todos os microrganismos utilizados nos ensaios fungitóxicos tiveram seu crescimento micelial 
inibidopelo óleo essencial de capim-limão e pelo citral e que os menores valores de concentração mínima inibitória e de crescimento micelial em relação à inibição micelial de todos os fitopatógenos utilizados foram apresentados pelo citral.

Corroborando com Guimarães et al., (2011) sobre a ação atifungica do óleo essência de Cymbopogon citral, Silva et al., (2017) realizou um estudo com a finalidade de verificar a ação do óleo essencial de Cymbopogon citral determinando a concentração inibitória mínima e a concentração fungicida mínima para Candida albicans, Candida tropicalis e Candida tropicalis cepas, bem como analisar o possível mecanismo de ação do óleo através da adição de sorbitol ao meio de cultura. Como resultado observaram que determinado que a concentração inibitória mínima para Candida albicans foi $125 \mu \mathrm{g} / \mathrm{mL}$, enquanto para Candida tropicalis foi $250 \mu \mathrm{g} / \mathrm{mL}$ e que a adição do sorbitol não potencializou a ação do óleo essencial. Verificaram que o óleo essencial de Cymbopogon citratus age como potente fungicida sobre esses fungos.

Já Santos; Vogel, (2012) em um estudo feito com objetivo de verificar a eficácia in vitro do óleo de capim- cidreira (Cymbopogon citratus) sobre fêmeas ingurgitadas de Rhipicephalus (Boophilus) microplus por meio do exame de biocarrapaticidograma, concluiu que o óleo de C. citratus apresenta controle parcial em teleóginas ingurgitadas de $R$. microplus em ensaios in vitro, e, após avaliações in vivo, pode possuir um uso promissor como carrapaticida, inclusive em populações resistentes a bases químicas.

Quanto sua ação calmante Medeiros, Cavalcante, Moura, Wanderley e Souza (2021) avaliaram pacientes com transtornos de ansiedade e insônia por consequência da infecção do novo coronavírus. Verificaram resultados satisfatórios. Os autores ressaltam que podem ser preparadas a infusões tendo como indicação terapêutica a ingesta de $150 \mathrm{~mL}$ três vezes ao dia para alcance do efeito calmante nos transtornos de ansiedade e distúrbios do sono.

Ainda sobre a ação no sistema nervoso Portela, (2017), realizou um estudo com objetivando a identificação de alternativas fitoterápicas utilizadas para tratamento da insônia pela comunidade carcerária no município de Canindé. Neste estudo foram utilizados Cymbopogon citratus e Melissa officinalis onde estes fitoterápicos foram testados no período de 05 meses. Ao final os participantes que utilizaram Cymbopogon citratus, 92\% acharam positivos seus efeitos para tratar a insônia e dos pacientes que usaram a Melissa officinalis, $88 \%$ aprovaram a sua eficácia no tratamento da insônia.

Com relação a propriedade anti-hipertensiva das plantas, esta baseia-se na produção de metabólitos secundários que atuam sobre diferentes mecanismos, promovendo a diminuição da pressão arterial. E a planta em estudo demonstra ações vasodilatadora, hipotensora, diurética e natriurética, contribuindo para o efeito anti-hipertensivo (Alves \& Santos, 2017).

\section{Considerações Finais}

O capim cidreira (Cymbopogon citratus) tem se apresentado como eficaz no auxílio do tratamento da hipertensão arterial, possui efeito calmante, antiespasmódico, analgésico entre outros. Essas ações terapêuticas são produzidas, principalmente, pela presença do citral, componente em maior quantidade no óleo essencial desta erva.

Por ter eficácia comprovada de seus benéficos e sendo este de fácil cultivo, tem-se nesta erva um fitoterápico de fácil acesso para população em geral, tanto para controle de moléstias humanas quanto para controle de pragas em animais.

\section{Referências}

Aluyor, E. O \& Oboh. I. O. (2014), Enciclopédia de Microbiologia Alimentar (segunda edição).137-140.

Alves, C. M \& Santos, M. C. P. F (2017). Plantas medicinais utilizadas no tratamento da hipertensão arterial no município de Cuité/PB. II Congresso Brasileiro de Ciências de Saúde.

Avoseh, O., Oyedeji, O., Rungqu, P. Chungag, B. N \& Oyedeji, A. (2015). Cymbopogon Species; Ethnopharmacology, Phytochemistry and the Pharmacological Importance Molecules, 20(5), 7438-7453.https://doi.org/10.3390/molecules20057438 
Azevedo, R. R. S., Almeida, V. G. A., Silva, E. M. F., Lira, A. S., Gomes, N. R. S., Matias, T. M. S., Souza, L. I. O \& Feitosa, A. S. (2011). Potencial antioxidante e antibacteriano do extrato etanólico de plantas usadas como chás. Revista Semente, 6(6). https://revistas.cesmac.edu.br/index.php/semente/article/view/162

Azevêdo, T. K. B., Paes, J. B., Colegare, L \& Santana, G. M. (2017). Teor de Taninos Condensados Presente na Casca de Jurema-Preta (Mimosa tenuiflora) em Função das Fenofases. Floresta e Ambiente, 24, e00026613. https://doi.org/10.1590/2179-8087.026613

Badke, M. R., Budó, M. L. D., Titonelli, N. A. A., Zanetti, G. D \& Heisler, E. V. (2012). Saberes e práticas populares de cuidado em saúde com o uso de plantas medicinais. Texto \& Contexto-Enfermagem, 21(2), 363-370. https://doi.org/10.1590/S0104-07072012000200014

Bernardes, N. R., Glória, L. L., Nunes, C. R., Pessanha, F. F., Muzitano, M. F., \& Oliveira, D. B. (2011). Quantificação dos teores de taninos e fenóis totais e avaliação da atividade antioxidante dos frutos de Aroeira. Vértices, 13(3), 117-28.

Boukhatem, M. N., Kameli, A., Ferhat, M. A., Saidi, F \& Tayebi, K. O potencial conservante de alimentos dos óleos essenciais: o capim-limão é a resposta? (2014). J. Verbr. Lebensm, 9, 13-21. https://link.springer.com/article/10.1007/s00003-013-0852-x

Brasil. Agência Nacional de Vigilância Sanitária - Anvisa. Medicamentos fitoterápicos e plantas medicinais. (2020). https://www.gov.br/anvisa/ptbr/assuntos/medicamentos/fitoterapicos.

Brasil. Agência Nacional de Vigilância Sanitária. Formulário de Fitoterápicos da Farmacopeia Brasileira / Agência Nacional de Vigilância Sanitária. Brasília: Anvisa. (2011). https://portalarquivos2.saude.gov.br/images/pdf/2014/julho/14/Formulario-de-Fitoterapicos-da-Farmacopeia-Brasileira-sem-marca.pdf.

Brasil. Instituto Nacional de Metrologia, Normalização e Qualidade Industrial -INMETRO. (2021). http://www.inmetro.gov.br/consumidor/produtos/cha.asp .

Brito, E. S., Garruti, D. D. S., Alves, P. B., \& Blank, A. F. (2011). Caracterização odorífera dos componetes do óleo essencial de capim-santo (Cymbopogon citratus (DC.) stapf., Poaceae) por cromatografia gasosa (CG)-olfatometria. Embrapa Agroindústria Tropical-Boletim de Pesquisa e Desenvolvimento (INFOTECA-E). https://www.infoteca.cnptia.embrapa.br/bitstream/doc/900884/1/BPD11001.pdf

Comachio, G., \& Prevedello, M. T. (2021). Antioxidantes e sua relação com os radicais livres, e Doenças Crônicas Não Transmissíveis: uma revisão de literatura. Brazilian Journal of Development, 7(6), 55244-55285. https://www.brazilianjournals.com/index.php/BRJD/article/view/30840

Costa, G. F. F. (2015). Cymbopogon citratus and its polyphenols as potential phytotherapeutic products: an in vivo approach (Doctoral dissertation, Universidade de Coimbra (Portugal)). https://www.proquest.com/openview/27c8fce798caf9586947cc49b72467d7/1?pq-origsite=gscholar\&cbl=2026366

Felipe, L. O., \& Bicas, J. L. (2017). Terpenos, aromas e a química dos compostos naturais. Química Nova na Escola, 39(2), 120-130. http://dx.doi.org/10.21577/0104-8899.20160068

Fonseca, R. C., \& Giotto, A. C. (2021). Utilização E Conhecimentos De Discentes Sobre Plantas Medicinais E Fitoterápicos. Revista de Iniciação Científica e Extensão, 4(1), 613-23. https://revistasfacesa.senaaires.com.br/index.php/iniciacao-cientifica/article/view/322/259

Garlet, T. M. B. Plantas medicinais nativas de uso popular no Rio Grande do Sul [recurso eletrônico] /Cartilha-Plantas-Medicinais - Santa Maria, RS: UFSM, PRE. (2019). https://www.ufsm.br/app/uploads/sites/346/2019/12/Cartilha-Plantas-Medicinais.pdf.

Gbenou, J. D., Ahounou, J. F., Hugete. B. A., Laleye, A., Yayi, E., Gbaguidi, F., Moussa, L. B., Darboux, R., Dansou, P., Moudachirou, M., \& Kotchoni, S. O. (2013). Composição fitoquímica dos óleos essenciais de Cymbopogon citratus e Eucalyptus citriodora e suas propriedades antiinflamatórias e analgésicas em ratos Wistar. Relatórios de biologia molecular, 40 (2), 1127-1134. https://link.springer.com/article/10.1007/s11033-012-2155-1

Gomes, E. C., \& Negrelle, R. R. B. (2015). Análise da cadeia produtiva do capim limão: estudo de caso. Revista Brasileira de Plantas Medicinais, 17, 201209. https://doi.org/10.1590/1983-084X/10_077

Guimarães, L. G. D. L., Cardoso, M. D. G., Sousa, P. E. D., Andrade, J. D., \& Vieira, S. S. (2011). Atividades antioxidante e fungitóxica do óleo essencial de capim-limão e do citral. Revista Ciência Agronômica, 42, 464-472. https://www.scielo.br/j/rca/a/MjxmmxfFtg3WXB5p3WtLPJp/?format=pdf\&lang=pt

Jesus, J. G. D. (2019). Elaboração de fórmulas farmacêuticas de uso tópico utilzando óleo essencial extraído do capim cidreira. Tese (Mestrado em Processos

Lacerda, J. R. C., Silva, S. J., Sousa, L. C. F. S., Borges, M. D. G. B., Ferreira, R. T. F. V., Salgado, A. B., \& da Silva, M. J. S. (2013). Conhecimento popular sobre plantas medicinais e sua aplicabilidade em três segmentos da sociedade no município de Pombal-PB. Agropecuária Científica no Semiárido, 9(1), 14-23. http://revistas.ufcg.edu.br/acsa/index.php/ACSA/article/view/250

Lima, A. A. de, Alexandre, U. C.., \& Santos, J. S. (2021). The use of marijuana (Cannabis sativa L.) in the pharmaceutical industry: a review. Research, Society and Development, 10(12), e46101219829. https://doi.org/10.33448/rsd-v10i12.19829

Lins, A. D. F., Oliveira, M. N., Fernandes, V. O., Rocha, A. P. T., Sousa, F. C., Martins, A. N. A., \& Nunes, E. N. (2015). Quantificação de compostos bioativos em erva cidreira (Melissa officinalis L.) e capim cidreira (Cymbopogon citratus (dc) Stapf.). Gaia Scientia, 9(1), 17-21.

Lucena, B. F., Tintino, S. R., Figueredo, F. G., Oliveira, C. D. D. M., Aguiar, J. J. D. S., Cardoso, E. D. N., Aquino, P. A. E., Coutinho, H. D. M., \& Matias, E. F. (2015). Avaliação da atividade antibacteriana e moduladora de aminoglicosídeos do óleo essencial de Cymbopogon citratus (DC.) Stapf. Acta Biologica Colombiana, 20(1), 39-45. https://www.redalyc.org/pdf/3190/319033067005.pdf

Magalhães, B. E. A \& Santos, W. N. L. (2021). Capacidade antioxidante e conteúdo fenólico de infusões e decocções de ervas medicinais. Almeida Júnior, S. Produtos Naturais e Suas Aplicações: da comunidade para o laboratório. Guarujá, SP: Científica Digital, 234-247. https://downloads.editoracientifica.org/articles/210203148.pdf

Marques, J. P., \& Lopes, G. C. (2015). Alcaloides como agentes antitumorais: considerações químicas e biológicas. Revista Uningá Review, 24(1). http://revista.uninga.br/index.php/uningareviews/article/view/1674 
Medeiros, K. A., Cavalcante, C. C. N., Moura, P. E. A., Wanderley, T. L. R., \& Souza, F., M. M. M. (2021). A Fitoterapia Como Auxiliar Nos Cuidados Dos Transtornos De Ansiedade E Insônia Do Paciente Acometido Pela COVID-19. Revista Multidisciplinar em Saúde, 2(1), 29-29. https://doi.org/10.51161/rems/1045

Miranda, V. C. (2012). Influência de condições de secagem, sombreamento, horário de colheita e procedência das plantas sobre o teor de óleo essencial de Cymbopogon citratus (D.C) Stapf. Tese (Pós-graduação em Produção vegetal), Universidade Federal do Tocantins, Gurupi.

Oladeji, O. S., Adelowo, F. E., Ayodele, D. T., \& Odelade, K. A. (2019). Fitoquímica e atividades farmacológicas de Cymbopogon citratus: Uma revisão. Scientific African, 6, e00137. https://doi.org/10.1016/j.sciaf.2019.e00137

Oliveira, D. M. D., \& Bastos, D. H. M. (2011). Biodisponibilidade de ácidos fenólicos. Química Nova, 34, 1051-1056. https://doi.org/10.1590/S010040422011000600023

Oliveira, L., Barcelos, J., Ferreira, S. I., Rodrigues, O., \& Sardinha, T. (2019). Estudo da atividade antioxidante do extrato bruto hidroalcoólico do capimcidreira (Cymbopogon citratus) pelo método DPPH. Enciclopédia Biosfera, 16(29). https://doi.org/10.18677/EnciBio_2019A157

Pereira, P. R., \& Ruyz, L. L. P. (2018) Ações terapêuticas do capim-santo: uma revisão de literatura. Revista Saúde em Foco, 10. https://portal.unisepe.com.br/unifia/wp-content/uploads/sites/10001/2018/06/034_A\%C3\%87\%C3\%95ES_TERAP\%C3\%8AUTICAS_DO_CAPIMSANTO.pdf

Pereira, R. J., \& Cardoso, G. M. (2012). Metabólitos secundários vegetais e benefícios antioxidantes. Journal of biotechnology and biodiversity, 3(4). https://www.todafruta.com.br/wp-content/uploads/2016/09/Metab\%C3\%B3litos-secund\%C3\%A1rios-ARTIGO.pdf

PORT'S, P. S.V. (2011). Compostos fenólicos e potencial antioxidante de ervas consumidas na região amazônica brasileira. Tese (Mestre em Ciência de Alimentos), Universidade Estadual de Campina, Campinas - SP.. http://repositorio.unicamp.br/handle/REPOSIP/254810

Portela, J. G. G. (2017). Estudo de utilização do Cymbopogon citratus e da Melissa officinalis em uma unidade carcerária. Universidade Federal Do Ceará UFC. https://ares.unasus.gov.br/acervo/handle/ARES/20399

Químicos e biotecnológico) - Universidade Tecnológica Federal do Paraná, Toledo-PR. http://riut.utfpr.edu.br/jspui/handle/1/23827

Ramos, L. R., Santos, J. S., Daguer, H., Valese, A. C., Cruz, A. G., \& Granato, D. (2017). Analytical optimization of a phenolic-rich herbal extract and supplementation in fermented milk containing sweet potato pulp. Food Chemistry, 221, 950-958. https://doi.org/10.1016/j.foodchem.2016.11.069

Rezende, F. M., Rosado, D., Moreira, F. A., \& de Carvalho, W. R. S. (2016). Vias de síntese de metabólitos secundários em plantas. Laboratório de Ensino de Botânica, 93. https://www.researchgate.net/profile/Carolina-Kleingesinds/publication/324744075_Sinalizacao_entre_plantas_e_bacterias/link s/5adfdf 970f7e9b 285945e501/Sinalizacao-entre-plantas-e-bacterias.pdf\#page=93

Rocha, W. S., Lopes, R. M., Silva, D. B. D., Vieira, R. F., Padilha, J. P. D., \& Costa, T. A. D. S. (2011). Compostos fenólicos totais e taninos condensados em frutas nativas do cerrado. Revista Brasileira de Fruticultura, 33(4), 1215-1221. https://doi.org/10.1590/S0100-29452011000400021

Rodrigues, S. L., Martins, L. D. V., Bantim, F. C. I., Meireles, D. M. D. S., Ferreira, P. M. P., \& Peron, A. P. (2015). Flavonóides: constituição química, ações medicinais e potencial tóxico. Acta $\quad$ toxicológica https://www.toxicologia.org.ar/bibliotecavirtual/acta_toxicologica/vol_23_1/rodrigues.pdf

Roma, R. M. (2020). Relatório de Estágio e Monografia intitulada "Atividades biológicas de Cymbopogon citratus (DC.) Stapf (Doctoral dissertation, Universidade de Coimbra). https://estudogeral.sib.uc.pt/handle/10316/93106

Roriz, C. L, Barros, L., Carvalho, A. M, Santos, B. C., \& Ferreira, I. C. (2014). Pterospartum tridentatum, Gomphrena globosa e Cymbopogon citratus: Um estudo fitoquímico com foco em compostos antioxidantes. Food Research International, 62, 684-693. https://bibliotecadigital.ipb.pt/handle/10198/11450

Santos, A., Paduan, R. H., Gazin, Z. C., Jacomassi, E., Oliveira, P. S., Garcia, D. A. G., \& Cortez, L. E. R. (2009). Determinação do rendimento e atividade antimicrobiana do óleo essencial de Cymbopogon citratus (DC.) Stapf em função de sazonalidade e consorciamento. Revista Brasileira de Farmacognosia, 19(2A), 436-441. https://doi.org/10.1590/S0102-695X2009000300017

Santos, F. D., \& Vogel, F. S. F. (2012). Avaliação in vitro da ação do óleo essencial de capim limão (Cymbopogon citratus) sobre o carrapato bovino Rhipicephalus (Boophilus) microplus. Revista Brasileira de Plantas Medicinais, 14, 712-716. https://doi.org/10.1590/S1516-05722012000400020

Santos, V. S. Capim-santo. Mundo Educação - UOU. (2021). https://mundoeducacao.uol.com.br/saude-bem-estar/capimsanto.htm

Shah, G., Shri, R., Panchal, V., Sharma, N., Singh, B \& Mann, A. S. (2011). Scientific basis for the therapeutic use of Cymbopogon citratus, stapf (Lemon grass), Journal of Advanced Pharmaceutical Techonology e Research, 2(1), 3-8. https://doi.org/10.4103/2231-4040.79796

Silva, A. C. O. D., \& Lima. R. A. (2015). Identificação das classes de metabólitos secundários no extrato etanólico dos frutos e folhas de Eugenia uniflora L. epositorio.saolucas.edu.br:8080/xmlui/bitstream/handle/123456789/1446/Ana\%20Cristina\%20Oliveira\%20da\%20Silva\%20-

Identifica $\%$ E7\%E3o\%20das $\% 20$ classes $\% 20 \mathrm{de} \% 20$ metab $\%$ F3litos $\% 20$ secund $\%$ E1rios $\% 20$ no $\% 20$ extrato $\% 20$ etan $\%$ F3lico $\% 20 \mathrm{dos} \% 20$ frutos $\% 20 \mathrm{e} \% 20$ folhas

$\% 20$ de $\% 20$ Eugenia $\% 20$ uniflora $\% 20$ L..pdf?sequence $=1$

Silva, N. L., Araújo, Í. P. C., Batista, M. R. F., Santos, T. B. A., Fernando, W. L., \& Amaral, F. R. (2017). Determinação da atividade antioxidante e teor de flavonoides totais equivalentes em quercetina em folhas de Cymbopogon citratus (dc) stapf e Melissa officinalis lam. Conexão cientifica, 12(1), 46-53. https://doi.org/10.24862/cco.v12i1.499

Souza, É. E. D., Ribeiro, M. D. F., Sodre, L. F., Soares, I. M., Marson, P. G., \& Ascêncio, S. D. (2015). Perfil fitoquímico das folhas de uma variedade de Cymbopogon citratus cultivada no município de palmas-to. In $6^{a}$ JICE-Jornada de Iniciação Científica e Extensão. https://propi.ifto.edu.br/ocs/index.php/jice/6jice/paper/view/7019 
Research, Society and Development, v. 10, n. 12, e263101220281, 2021

(CC BY 4.0) | ISSN 2525-3409 | DOI: http://dx.doi.org/10.33448/rsd-v10i12.20281

Stefanello, S., Kozera, C., Ruppelt, B. M., Fumagalli, D., Camargo, M. P., \& Sponchiado, D. (2018). Levantamento do uso de plantas medicinais na Universidade Federal do Paraná, Palotina-PR, Brasil. Extensão em Foco, 1(15). http://dx.doi.org/10.5380/ef.v1i15.52776

Tontini, J. F., Silva, J. A., Souza, F. M., \& Poli, C. H. E. C. (2020). Respostas na fisiologia da digestão ruminal ao uso de taninos na alimentação de ruminantes. $\quad P U B V E T, \quad 15, \quad 168 . \quad$ https://www.pubvet.com.br/artigo/7543/respostas-na-fisiologia-da-digestatildeo-ruminal-ao-uso-de-taninos-naalimentaccedilatildeo-de-ruminantes

Vellosa, J. C. R., Biavatti, M., Françóia, P. C. O., de Mello, B. J., de Almeida, A. C., \& Bueno, G. E. (2021). Estresse oxidativo: uma introdução ao estado da arte. Brazilian Journal of Development, 7(1), 10152-10168. https://www.brazilianjournals.com/index.php/BRJD/article/view/23823 